\title{
Effect of Leflunomide on Pegloticase Response Rate in Patients with Uncontrolled Gout: A Retrospective Study
}

\author{
Karim Richard Masri · Lissa Padnick-Silver · Kevin Winterling • \\ Brian LaMoreaux (ID
}

Received: November 16, 2021 / Accepted: December 20, 2021 / Published online: January 8, 2022

(c) The Author(s) 2022

\begin{abstract}
Background: Pegloticase, a PEGylated uricase for uncontrolled gout, rapidly lowers serum urate (SU). Not all patients complete a fulltherapy course because anti-pegloticase antibodies can develop, causing efficacy loss and infusion reactions. The literature and clinical trial data indicate that methotrexate co-administration markedly improves pegloticase response rates from the established monotherapy response rate of $42 \%$. Unfortunately, methotrexate use is restricted by kidney disease, which is often present in uncontrolled gout patients. Leflunomide is less restricted in patients with renal dysfunction. This study examined the treatment response rate of pegloticase co-administered with leflunomide.

Methods: Patients co-treated with pegloticase (8 $\mathrm{mg}$ biweekly infusion) and oral leflunomide (20 mg/day) were included. Patient/treatment characteristics and safety parameters (adverse events [AEs], laboratory parameters) were
\end{abstract}

\section{K. R. Masri}

Bon Secours Rheumatology Center, Richmond, VA, USA

L. Padnick-Silver · K. Winterling · B. LaMoreaux

Horizon Therapeutics, Lake Forest, IL, USA

B. LaMoreaux $(\square)$

1 Horizon Way, Deerfield, IL 600615, USA

e-mail: blamoreaux@horizontherapeutics.com examined. Pre-infusion prophylaxis was administered (day of infusion: IV solumedrol, night before and morning of infusion: oral fexofenadine or diphenhydramine). Patients were considered treatment responders if $\geq 12$ pegloticase infusions were administered and pre-infusion $\mathrm{SU}<6 \mathrm{mg} / \mathrm{dl}$ at infusion- 12 .

Results: Ten patients (five male, $72.7 \pm 12.5$ years) were included. The most common comorbidities were chronic kidney disease (90\%), hypertension (70\%), diabetes mellitus (60\%), obesity (60\%), and congestive heart failure (50\%). Baseline SU was $7.1 \pm 2.4 \mathrm{mg} / \mathrm{dl}$ and nine patients (90\%) had subcutaneous tophi noted. Seven patients (70\%) met responder criteria, receiving $26.6 \pm 14.0$ infusions (range 13-55) with a preinfusion-12 SU of $0.9 \pm 1.5 \mathrm{mg} / \mathrm{dl}$. The three non-responders received $<12$ infusions because of unrelated AEs or loss of follow-up. Three patients (30\%) experienced AEs. One had unrelated cardiac disease worsening and three gout flares, one had a pre-infusion solumedrol reaction (wooziness/loss of consciousness), and one had two mild, transient increases in liver enzymes.

Conclusions: This study supports leflunomide as co-therapy to pegloticase in uncontrolled gout patients. Heterogeneity and high comorbidity burden in uncontrolled gout patients makes having a variety of immunomodulators options important. 
Keywords: Uncontrolled gout; Refractory gout; Pegloticase; Leflunomide; Immunomodulation

\section{Key Summary Points}

Why carry out this study?

Co-administering methotrexate with pegloticase markedly improves treatment response rates but other immunomodulators, including leflunomide, may be better suited for patients with chronic kidney disease, a common comorbid condition in uncontrolled gout patients.

This retrospective study examined treatment response rates in uncontrolled gout patients treated with pegloticase plus leflunomide co-therapy (responder defined as $\geq 12$ pegloticase infusions with serum urate $<6 \mathrm{mg} / \mathrm{dl}$ just prior to infusion 12).

\section{What was learned from the study?}

Seven of ten patients (70\%) met treatment response criteria, receiving $26.6 \pm 14.0$ infusions (pre-infusion-12 serum urate: $0.9 \pm 1.5 \mathrm{mg} / \mathrm{dl})$.

Three patients (30\%) experienced an adverse event, with one experiencing unrelated worsening of cardiac disease and three gout flares, one experiencing a pre-infusion solumedrol reaction (wooziness/loss of consciousness), and one experiencing two mild, transient increases in liver enzymes.

This study supports leflunomide as cotherapy to pegloticase in uncontrolled gout patients. This is important because due to heterogeneity and high comorbidity burden of these patients, a variety of immunomodulator options are needed.

\section{INTRODUCTION}

Pegloticase is a PEGylated biologic for uncontrolled gout that has well-established serum urate (SU)-lowering effects [1]. However, many patients develop anti-drug antibodies (ADAs) to pegloticase, which have been associated with loss of treatment response and increased risk for infusion reactions (IRs) [2]. As a result, clinical trial data showed a $42 \%$ pegloticase monotherapy treatment response rate, with loss of uratelowering response noted in many patients and a high IR rate in non-responders. In these phase 3 trials, subjects received 12 biweekly pegloticase infusions ( $8 \mathrm{mg}$ ) over 24 weeks. Sustained uratelowering with a full course of pegloticase is important. At week 24 in the pegloticase clinical trials, nearly $70 \%$ of pegloticase responders had resolution of at least one tophus [3]. In contrast, only $28 \%$ of non-responders had similar tophi improvement [3]. This is notable because tophaceous gout patients have a greater disease burden [4] and higher comorbidity prevalence [5] than non-tophaceous patients. Additionally, and importantly, the uncontrolled gout population has few effective treatment options and, for many patients, pegloticase is their last hope.

Emerging data indicate that co-treatment with pegloticase and immunomodulating agents may allow more patients to receive and respond to a full treatment course. Prior studies describe increased success of pegloticase treatment in conjunction with methotrexate [6-10], mycophenolate mofetil [11], azathioprine [12], or cyclosporine [8]. Though methotrexate cotherapy has been studied in the highest number of patients [13], its use in patients with renal impairment is limited by a resulting increase in methotrexate toxicity [14]. Given that chronic kidney disease (CKD) is prevalent in uncontrolled gout patients [15-17], this is of particular importance. The use of leflunomide is not as restricted by $\mathrm{CKD}$, as no signs of renal toxicity, including increased serum creatinine, were observed during clinical phase 3 clinical trials in patients with rheumatoid arthritis [14]. However, those trials did not include patients with significant renal dysfunction [18, 19] and, as stated in the leflunomide package insert, 
caution should be used when administering leflunomide to patients with kidney dysfunction [20]. To date, the literature does not contain information on the use of leflunomide with pegloticase. This report fully describes treatment response rate and safety observations in patients with uncontrolled gout co-treated with leflunomide and pegloticase.

\section{METHODS}

This retrospective study was reviewed and approved by the Western Institutional Review Board (IRB; Puyallup, WA, USA), which designated this study as exempt research waiving the requirement of informed consent. All study conduct adhered to the tenets of the Helsinki Declaration of 1964 and its later amendments.

All included patients had received care at a private rheumatology practice where an immunomodulatory agent is often used in conjunction with pegloticase to maximize chances of sustained urate-lowering response. All patients were heavily burdened by gout and, as with all patients administered pegloticase, were closely monitored with physical exams, vital sign monitoring, and laboratory testing. In this community practice, leflunomide is used in place of methotrexate as the co-therapy agent when an uncontrolled gout patient has comorbid renal dysfunction or another condition that would exclude methotrexate use. Patients that had been co-treated with pegloticase (biweekly $8 \mathrm{mg}$ infusions) and oral leflunomide (10 mg/day for 7 days, followed by $20 \mathrm{mg} /$ day) were included in this retrospective study. Prior to each infusion, all patients were administered a standard prophylaxis regimen of intravenous solumedrol $(125 \mathrm{mg})$ on the day of infusion and either oral fexofenadine $(60 \mathrm{mg})$ or diphenhydramine $(25 \mathrm{mg})$ the night before and day of infusion. As instructed in the pegloticase package insert [21], SU was monitored prior to each infusion to monitor for loss of urate-lowering effect, known to precede infusion reaction in many patients [22]. Liver function and blood cell count changes are of concern in patients administered leflunomide. Therefore, liver function tests and blood cell counts were also measured prior to each infusion throughout pegloticase therapy. Because of the high frequency of renal dysfunction in uncontrolled gout patients [16, 17], kidney function by means of serum creatinine level was also monitored.

Extracted data included patient demographics, gout characteristics, serum urate (SU), number of pegloticase infusions, and leflunomide timing with respect to the first pegloticase infusion. Safety data examined included clinical laboratory parameters and adverse events, with particular attention paid to gout flares and IRs. The primary outcome was the proportion of pegloticase responders, defined as those receiving at least 12 infusions with an $\mathrm{SU}<6 \mathrm{mg} / \mathrm{dl}$ just prior to infusion 12. Data are presented as mean \pm standard deviation and $n$ (\%) as appropriate.

\section{RESULTS}

Ten patients with uncontrolled gout who underwent pegloticase with leflunomide cotreatment were identified and included in analyses (Table 1). All patients were either intolerant of or no longer responded to oral ULTs. Nine of ten patients had visible tophi and all had severe manifestations of gout, including chronic pain, frequent gout flares, erosive joint damage (radiographically evidenced), and/or gout-related hospitalizations. As a result, gout heavily impacted patient quality of life in all included cases. Five patients $(50 \%)$ were male, there were no current smokers, and average patient age was $72.7 \pm 12.5$ years. Gout disease duration widely varied between 2 and 20 years, $90 \%$ had subcutaneous tophi, and SU prior to the first pegloticase infusion averaged $7.1 \pm 2.4 \mathrm{mg} / \mathrm{dl}$. Comorbidities were prevalent, with CKD (90\%), hypertension (70\%), diabetes mellitus (60\%), obesity (60\%), and congestive heart failure (50\%) most reported (Table 1). Liver function tests were within two times the upper limit of normal (ULN) in all patients for both ALT $(25.3 \pm 8.3 \mathrm{U} / \mathrm{l})$ and AST $(33.9 \pm 21.3$ $\mathrm{U} / \mathrm{l})$. No patient had a history of liver disease, with the exception of one patient (patient 8), who had a remote history of prior hepatitis $B$ 
Table 1 Patient demographic and clinical characteristics

\begin{tabular}{|c|c|c|c|c|c|c|}
\hline $\begin{array}{l}\text { Patient } \\
\text { number }\end{array}$ & Gender & Age (years) & $\begin{array}{l}\text { BMI kg/ } \\
\left.\mathbf{m}^{2}\right)\end{array}$ & $\begin{array}{l}\text { Pre-therapy } \\
\text { SU (mg/dl) }\end{array}$ & $\begin{array}{l}\text { Visible } \\
\text { tophi }\end{array}$ & Comorbidities \\
\hline 1 & Male & 47 & 29.1 & 9.4 & Yes & $\begin{array}{l}\text { Hypertension, CHF, CKD (stage } 3 \text {, } \\
\text { polycystic) }\end{array}$ \\
\hline 2 & Female & 70 & 36.5 & 9.3 & No & $\begin{array}{l}\text { Hypertension, CHF, CKD (stage 4), } \\
\text { diabetes mellitus, obesity, bipolar, post- } \\
\text { menopausal }\end{array}$ \\
\hline 3 & Male & 70 & 26.8 & 10.2 & Yes & $\begin{array}{l}\text { Hypertension, CHF, coronary artery disease, } \\
\text { CKD (stage 4), diabetes mellitus, atrial } \\
\text { fibrillation, transient ischemic attack, } \\
\text { vitamin D deficiency, alcohol use }\end{array}$ \\
\hline 4 & Female & 63 & 31.7 & $3.8^{\mathrm{a}}$ & Yes & Coronary artery disease, CKD, obesity \\
\hline 5 & Male & 83 & 24.0 & $5.5^{\mathrm{a}}$ & Yes & $\begin{array}{l}\text { CKD, diabetes mellitus, dyslipidemia, history } \\
\text { of rectal cancer }\end{array}$ \\
\hline 6 & Male & 72 & 39.4 & 9.0 & Yes & Hypertension, CKD, obesity \\
\hline 7 & Female & 81 & 41.6 & $4.5^{\mathrm{b}}$ & Yes & $\begin{array}{l}\text { Hypertension, CHF, CKD (stage 3-4), } \\
\text { diabetes mellitus, obesity, seronegative } \\
\text { rheumatoid arthritis, chronic obstructive } \\
\text { pulmonary disease, gastroesophageal reflux } \\
\text { disease, asthma, sleep apnea, inflammatory } \\
\text { arthritis }\end{array}$ \\
\hline 8 & Male & 81 & 44.1 & 7.8 & Yes & $\begin{array}{l}\text { Hypertension, CKD (stage 3), diabetes } \\
\text { mellitus, dyslipidemia, obesity, remote } \\
\text { history of hepatitis B infection, chronic } \\
\text { obstructive pulmonary disease, } \\
\text { gastroesophageal reflux disease, glaucoma, } \\
\text { neuropathy, lymphedema, benign prostate } \\
\text { hyperplasia, diverticulosis, kidney stones, } \\
\text { and pulmonary embolism }\end{array}$ \\
\hline 9 & Female & 92 & 22.3 & $4.6^{\mathrm{a}}$ & Yes & $\begin{array}{l}\text { Hypertension, CHF, CKD (stage 3), anemia, } \\
\text { apnea, alcohol abuse, gastric ulcer, hearing } \\
\text { loss, pneumonia, pancreatic cyst, spinal } \\
\text { stenosis, bile obstruction, degenerative } \\
\text { joint disease }\end{array}$ \\
\hline 10 & Female & 68 & 32.6 & 6.6 & Yes & $\begin{array}{l}\text { Diabetes mellitus, dyslipidemia, obesity, } \\
\text { osteoarthritis, asthma, cancer }\end{array}$ \\
\hline Mean \pm SD & & $72.7 \pm 12.5$ & $32.8 \pm 7.4$ & $7.07 \pm 2.37$ & & \\
\hline
\end{tabular}

$S U$ serum urate, $C H F$ congestive heart failure, $C K D$ chronic kidney disease

${ }^{a}$ Patient had a long history of $S U>6 \mathrm{mg} / \mathrm{dl}$ and had heavy gout burden

${ }^{\mathrm{b}}$ Post-infusion measurement 
infection (ALT $=21$, AST $=30$ at the beginning of treatment).

Leflunomide initiation varied between 30 weeks before and 27 weeks after pegloticase infusion 1 (median timing: 5.5 days before infusion 1). Leflunomide was initiated a mean of $9.9 \pm 11.8$ weeks before pegloticase in the five patients (50\%) pre-treated with leflunomide and $12.6 \pm 10.6$ weeks after pegloticase in the four patients $(40 \%)$ who began leflunomide after pegloticase. The remaining patient (10\%) initiated leflunomide on the same day as pegloticase infusion 1 . Seven patients (70\%) met treatment response criteria, receiving $\geq 12$ pegloticase infusions and having a mean preinfusion SU at infusion 12 of $0.90 \pm 1.46 \mathrm{mg} / \mathrm{dl}$ (range $0.1-3.8 \mathrm{mg} / \mathrm{dl}$, Table 2 ). In these seven responders, a mean of $26.6 \pm 14.0$ pegloticase infusions were administered (median 22, range 13-55 infusions). Of the three patients who did not meet treatment response criteria, one entered hospice after infusion 6 (SU prior to last infusion $<1 \mathrm{mg} / \mathrm{dl}$ ), one discontinued after infusion 9 due to unrelated worsening of congestive heart failure and CKD (SU prior to last infusion $<1 \mathrm{mg} / \mathrm{dl}$ ), and one was lost to followup after infusion 6 (SU prior to last infusion: $7.0 \mathrm{mg} / \mathrm{dl}$ ). The patient with a rise in SU had a 6-month treatment interruption between infusions 4 and 5 and initiated leflunomide 4 weeks prior to infusion 5 .

No new safety concerns were identified. Three of ten patients (30\%) experienced at least one adverse event. One patient had three gout flares during treatment and a worsening of heart failure and renal disease that were deemed unrelated to pegloticase with leflunomide cotherapy (Table 2). One patient required emergency care because of an adverse reaction to solumedrol (loss of consciousness, wooziness) prior to pegloticase infusion 14 (scheduled pegloticase infusion not administered and treatment discontinued). This patient did meet treatment responder criteria. Lastly, no meaningful changes in liver function tests occurred during treatment (mean change during treatment in ALT and AST of $6.6 \pm 20.3$ and $-1.1 \pm 22.8 \mathrm{U} / \mathrm{l}$, respectively), with the exception of one patient who experienced mild, transient increases in liver function tests following infusion 6 (alanine aminotransferase $[\mathrm{ALT}]=126$ units $/ \mathrm{l}$, aspartate aminotransferase $[\mathrm{AST}]=92$ units/l) and infusion 18 (ALT $=104$ units $/ \mathrm{l}$, AST $=64$ units/l). The patient continued treatment with both pegloticase and leflunomide, ultimately meeting response criteria. The patient who had a prior hepatitis $\mathrm{B}$ infection had liver function tests within two times the ULN at end of treatment (ALT $=48$, AST $=32$ after 34 pegloticase infusions). No other clinically meaningful laboratory value changes occurred.

\section{DISCUSSION}

The current case series demonstrates that leflunomide administered as co-therapy may safely increase pegloticase treatment response rates. This is the first case series to thoroughly examine this treatment regimen. Pegloticase monotherapy trials showed a $42 \%$ treatment response rate $(n=85)$ [1], but $70 \%$ of pegloticase plus leflunomide-treated patients reported here $(n=10)$ met treatment response criteria. In agreement, leflunomide has also been shown to increase therapy efficacy and safety when administered in conjunction with biologic therapies in patients with rheumatoid arthritis [23-25].

Preliminary evidence in the literature and that of the current case series suggests that lowto-moderate dose immunomodulation with a variety of therapies can increase the proportion of patients receiving a full course of pegloticase therapy, likely through attenuation of ADA formation [13]. Methotrexate has been most studied, with data from a preliminary open-label clinical trial showing $79 \%$ efficacy rate at 6 months [7]. However, many gout patients have limitations to methotrexate, including CKD, which affects up to $47 \%$ of gout patients $[15,24]$. Preliminary evidence from the current study suggests leflunomide can also be successfully used as co-therapy with pegloticase. Other reports on mycophenolate mofetil [11], azathioprine [12], and cyclosporin (single case) [8] as co-therapy have also shown improvements in pegloticase response rates. Given the complexity of and high comorbidity rate in 
Table 2 Pegloticase with leflunomide co-therapy details and list of adverse events

\begin{tabular}{|c|c|c|c|c|c|c|}
\hline $\begin{array}{l}\text { Patient } \\
\text { number }\end{array}$ & $\begin{array}{l}\text { Leflunomide } \\
\text { initiation }^{\mathrm{a}} \\
\text { (days) }\end{array}$ & $\begin{array}{l}\text { Number of } \\
\text { pegloticase } \\
\text { infusions }\end{array}$ & $\begin{array}{l}\text { Pegloticase } \\
\text { therapy } \\
\text { duration } \\
\text { (weeks) }\end{array}$ & $\begin{array}{l}\text { SU at Inf } \\
12(\mathrm{mg} / \\
\text { dl })\end{array}$ & $\begin{array}{l}\text { Treatment responder? (If } \\
\text { no, reason) }\end{array}$ & Adverse events \\
\hline 1 & +30 & 9 & 16 & - & $\begin{array}{l}\text { No-Discontinued therapy } \\
\text { due to AEs (deemed } \\
\text { unrelated to co-therapy) }\end{array}$ & $\begin{array}{l}\text { Three gout flares, } \\
\text { worsening of } \\
\text { CHF (not- } \\
\text { related) }\end{array}$ \\
\hline 2 & -11 & 22 & 48 & 0.1 & Yes & $\begin{array}{l}\text { Mild, transient } \\
\text { increase liver } \\
\text { function tests } \\
\text { (after infusions } 6 \\
\text { and 18) }\end{array}$ \\
\hline 3 & -14 & 13 & 23 & 2.0 & Yes & $\begin{array}{l}\text { Loss of } \\
\text { consciousness } \\
\text { (infusion 11), } \\
\text { reaction to } \\
\text { solumedrol } \\
\text { (prior to } \\
\text { infusion 14) }\end{array}$ \\
\hline 4 & +189 & 6 & 33 & - & $\begin{array}{l}\text { No-Lost to follow-up after } \\
\text { infusion } 6 \text {. Note: Patient } \\
\text { had a 6-month treatment } \\
\text { interruption between } \\
\text { infusions } 4 \text { and } 5 \text { because } \\
\text { of insurance issues. } \\
\text { Leflunomide started prior } \\
\text { to infusion } 5\end{array}$ & - \\
\hline 5 & +35 & 22 & 56 & 0.1 & Yes & - \\
\hline 6 & +98 & 22 & 45 & 0.1 & Yes & - \\
\hline $7^{\dagger}$ & -210 & $27,19,9$ & $57,37,16$ & 0.1 & Yes & - \\
\hline 8 & 0 & 34 & 71 & 3.8 & Yes & - \\
\hline 9 & -77 & 6 & 12 & - & $\begin{array}{l}\text { No-Discontinued upon } \\
\text { entering hospice }\end{array}$ & - \\
\hline 10 & -36 & 18 & 35 & 0.1 & Yes & - \\
\hline Mean $\pm S D$ & $0.4 \pm 104.9$ & $20.7 \pm 14.9$ & - & $0.9 \pm 1.5$ & $7(70 \%)$ & - \\
\hline
\end{tabular}


Table 2 continued

\begin{tabular}{lllllll}
\hline $\begin{array}{l}\text { Patient } \\
\text { number }\end{array}$ & $\begin{array}{l}\text { Leflunomide } \\
\text { initiation }^{\text {a }} \\
\text { (days) }\end{array}$ & $\begin{array}{l}\text { Number of } \\
\text { pegloticase } \\
\text { infusions }\end{array}$ & $\begin{array}{l}\text { Pegloticase } \\
\text { therapy } \\
\text { duration }^{b} \\
\text { (weeks) }\end{array}$ & $\begin{array}{l}\text { SU at Inf } \\
\mathbf{1 2}(\mathbf{m g} / \\
\text { dl) }\end{array}$ & $\begin{array}{l}\text { Treatment responder? (If } \\
\text { no, reason) }\end{array}$ & Adverse events \\
\hline Median & -5.5 & 20 & 40.1 & 0.1 & - & - \\
\hline
\end{tabular}

$C H F$ congestive heart failure, $C K D$ chronic kidney disease, $S D$ standard deviation

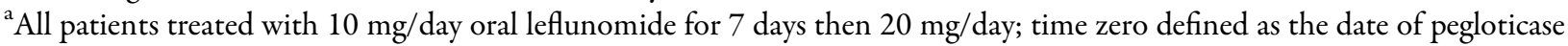
infusion $1,-$ indicates prior to infusion $1,+$ indicates after infusion 1

${ }^{\mathrm{b}}$ Therapy duration calculated as time between first and last pegloticase dose

${ }^{c}$ Patient 7 had been taking leflunomide as treatment for seronegative rheumatoid arthritis. The patient received two complete courses of pegloticase/leflunomide co-therapy (separated by 9 months) and was receiving a 3rd ongoing course at data collection (6 months gap between courses 2 and 3)

uncontrolled gout patients, data on the efficacy of a variety of immunomodulatory agents employed in this population as co-therapy with pegloticase are desirable.

Our study had several limitations. As with all retrospective studies, a selection bias may have been introduced. This was minimized by including all identified patients that qualified in the analyses. Second, our sample size was small at just ten patients, though was similar in size to multiple other existing reports $[6,8,10]$. Additionally, the timing of leflunomide initiation was variable, with some patients beginning leflunomide well into their pegloticase treatment course. Further, prospective studies are needed to determine the optimal timing for initiating leflunomide. Lastly, this retrospective study lacked a direct comparison to a pegloticase monotherapy group. Because of these considerations, larger, prospective, blinded, controlled trials are needed to fully understand the risk/benefit profile of leflunomide plus pegloticase co-therapy.

\section{CONCLUSIONS}

The current study provides preliminary evidence supporting the use of leflunomide as cotherapy with pegloticase in uncontrolled gout patients. The current case series is of particular importance because $90 \%$ of the included gout patients had CKD. These results and those presented in the literature suggest that a variety of immunomodulators may be viable options for co-therapy with pegloticase, giving clinicians several evidence-backed options for mitigating pegloticase immunogenicity in uncontrolled gout patients.

\section{ACKNOWLEDGEMENTS}

Funding. Funds provided by Horizon Therapeutics plc (Deerfield, IL) were used for thirdparty data collection fees, the Open Access Fee, and the Rapid Service Fee.

Authorship. All named authors meet the International Committee of Medical Journal Editors (ICMJE) criteria for authorship for this article, take responsibility for the integrity of the work as a whole, and have given their approval for this version to be published.

Author Contributions. Conceptualization: KRM, KW, BLM; Methodology: all authors; Formal analysis and investigation: LP-S; Writing-original draft preparation: LP-Silver; Writing review and editing: all authors; Funding acquisition: BLM; Resource: KRM, Supervision: KRM, BLM.

Medical Writing, Editing, Editorial, and Other Assistance. The authors acknowledge Timothy Bailey, DO, PhD, CMPP (The Lockwood Group; Stamford, CT) for assistance with 
data collection and Naina Barretto, PhD (Horizon Therapeutics; Deerfield, IL) for assistance with manuscript editing.

Prior Presentation. Preliminary findings of this study were presented at the 2020 Annual Meeting of the European League Against Rheumatism (June 3-6; virtual meeting) and the 2021 annual meeting of the European Crystal Network (March 4; virtual meeting).

Disclosures. Karim Richard Masri is a consultant and paid speaker for Horizon and a current stockholder. Lissa Padnick-Silver, Kevin Winterling, and Brian LaMoreaux are employees of and hold stock in Horizon.

Compliance with Ethics Guidelines. This retrospective study was reviewed and approved by the Western Institutional Review Board (IRB; Puyallup, Washington, USA), which designated this study as exempt research, waiving the requirement of informed consent. All study conduct adhered to the tenets of the Helsinki Declaration of 1964 and its later amendments.

Data Availability. The datasets generated during and/or analyzed during the current study are available from the corresponding author on reasonable request.

Open Access. This article is licensed under a Creative Commons Attribution-NonCommercial 4.0 International License, which permits any non-commercial use, sharing, adaptation, distribution and reproduction in any medium or format, as long as you give appropriate credit to the original author(s) and the source, provide a link to the Creative Commons licence, and indicate if changes were made. The images or other third party material in this article are included in the article's Creative Commons licence, unless indicated otherwise in a credit line to the material. If material is not included in the article's Creative Commons licence and your intended use is not permitted by statutory regulation or exceeds the permitted use, you will need to obtain permission directly from the copyright holder. To view a copy of this licence, visit http://creativecommons.org/licenses/by$\mathrm{nc} / 4.0 /$.

\section{REFERENCES}

1. Sundy JS, Baraf HS, Yood RA, et al. Efficacy and tolerability of pegloticase for the treatment of chronic gout in patients refractory to conventional treatment: two randomized controlled trials. JAMA. 2011;306:711-20.

2. Lipsky PE, Calabrese LH, Kavanaugh A, et al. Pegloticase immunogenicity: the relationship between efficacy and antibody development in patients treated for refractory chronic gout. Arthritis Res Ther. 2014;16:R60.

3. Mandell BF, Yeo AE, Lipsky PE. Tophus resolution in patients with chronic refractory gout who have persistent urate-lowering responses to pegloticase. Arthritis Res Ther. 2018;20:286.

4. Khanna PP, Nuki G, Bardin T, et al. Tophi and frequent gout flares are associated with impairments to quality of life, productivity, and increased healthcare resource use: results from a cross-sectional survey. Health Qual Life Outcomes. 2012;10: 117.

5. Lee KA, Ryu SR, Park SJ, Kim HR, Lee SH. Assessment of cardiovascular risk profile based on measurement of tophus volume in patients with gout. Clin Rheumatol. 2018;37:1351-8.

6. Botson JK, Peterson J. Pretreatment and coadministration with methotrexate improved durability of pegloticase response: an observational, proof-ofconcept case series. J Clin Rheumatol. 2020 [Epub ahead of print]. https://doi.org/10.1097/RHU. 0000000000001639.

7. Botson JK, Tesser JRP, Bennett R, et al. Pegloticase in combination with methotrexate in patients with uncontrolled gout: a multicenter, open-label study (MIRROR). J Rheumatol. 2021;48:767-74.

8. Bessen MY, Bessen SY, Yung CM. Concomitant immunosuppressant use with pegloticase in patients with tophaceous gout - a case series. Int J Clin Rheumatol. 2019;14:238-45.

9. Bessen SY, Bessen MY, Yung CM. Recapture and improved outcome of pegloticase response with methotrexate-a report of two cases and review of the literature. Semin Arthritis Rheum. 2019;49: 56-61. 
10. Albert JA, Hosey T, LaMoreaux B. Increased efficacy and tolerability of pegloticase in patients with uncontrolled gout co-treated with methotrexate: a retrospective study. Rheumatol Ther. 2020;7: 639-48.

11. Khanna PP, Khanna D, Cutter G, et al. Reducing immunogenicity of pegloticase with concomitant use of mycophenolate mofetil in patients with refractory gout: a phase II, randomized, doubleblind, placebo-controlled trial. Arthritis Rheumatol. 2021;73:1523-32.

12. Rainey H, Baraf HSB, Yeo A, Lipsky P. Companion immunosuppression with azathioprine increases the frequency of persistent responsiveness to pegloticase in patients with chronic refractory gout. Ann Rheumatic Dis. 2020;79:438.

13. Keenan RT, Botson JK, Masri KR, et al. The effect of immunomodulators on the efficacy and tolerability of pegloticase: a systematic review. Semin Arthritis Rheum. 2021;51:347-52.

14. Schiff $\mathrm{MH}$, Whelton A. Renal toxicity associated with disease-modifying antirheumatic drugs used for the treatment of rheumatoid arthritis. Semin Arthritis Rheum. 2000;30:196-208.

15. Francis-Sedlak M, LaMoreaux B, Padnick-Silver L, Holt RJ, Bello AE. Characteristics, comorbidities, and potential consequences of uncontrolled gout: an insurance-claims database study. Rheumatol Ther. 2021;8:183-97.

16. Singh JA, Cleveland JD. Gout is associated with a higher risk of chronic renal disease in older adults: a retrospective cohort study of U.S. Medicare population. BMC Nephrol. 2019;20:93.

17. Roughley MJ, Belcher J, Mallen CD, Roddy E. Gout and risk of chronic kidney disease and nephrolithiasis: meta-analysis of observational studies. Arthritis Res Ther. 2015;17:90.
18. Smolen JS, Kalden JR, Scott DL, et al. Efficacy and safety of leflunomide compared to placebo and sulphasalazine in active rheumatoid arthritis: a double-blind, ransomised, multicentre trial. Lancet. 1999;353:259-66.

19. Strand V, Cohen S, Schiff M, et al. Treatment of active rheumatoid arthritis with leflunomide compared with placebo and methotrexate. Arch Intern Med. 1999;159:2542-50.

20. ARAVA $^{\circledR}$ (leflunomide) [package insert]. SanofiAventis U.S. LLC, Bridgewater, NJ; February 2016. https://products.sanofi.us/arava/Arava.pdf. Accessed December 2, 2021.

21. KRYSTEXXA ${ }^{\circledR}$ (pegloticase) [package insert]. Horizon Therapeutics Ireland DAC, Dublin, Ireland; March 2021. https://www.hzndocs.com/ KRYSTEXXA-Prescribing-Information.pdf. Accessed December 2, 2021.

22. Keenan RT, Baraf HS, LaMoreaux B. Use of pre-infusion serum uric acid levels as a biomarker for infusion reaction risk in patients on pegloticase. Rheumatol Ther. 2019;6:299-304.

23. Kimyon G, Kalyoncu U, Kiraz S, et al. Biological and targeted-synthetic disease-modifying anti-rheumatic drugs with concomitant methotrexate or leflunomide in rheumatoid arthritis: real-life TReasure prospective data. Clin Exp Rheumatol. 2021;39:852-8.

24. Narváez J, Díaz-Torné C, Magallares B, et al. Comparative effectiveness of tocilizumab with either methotrexate or leflunomide in the treatment of rheumatoid arthritis. PloS One. 2015;10: e0123392.

25. Finckh A, Dehler S, Gabay C. The effectiveness of leflunomide as a co-therapy of tumour necrosis factor inhibitors in rheumatoid arthritis: a population-based study. Ann Rheum Dis. 2009;68:33-9. 